\title{
Population age structure Juniperus polycarpos C. Koch in arid conditions of Foothill Dagestan (dubkinsko-miatlinsky area)
}

\author{
Gulnara Sadykova *, and Nadezda Amirkhanova \\ Senior Researcher, Mountain Botanical Garden of the Dagestan Federal Research Center of the \\ Russian Academy of Sciences, 367000, M. Gadzhieva 45, Makhachkala, Russian Federatin
}

\begin{abstract}
The age composition of the population of the rare tree species Juniperus polycarpos C. Koch in Foothill Dagestan was studied according to the calendar age of individuals and their age states. The calendar age is determined by an index obtained as the number of annual rings per unit of radial growth of the trunk. Age states were assessed by vitality, productivity, infestation and size of individuals. The area occupied by the population, the number of individuals and the phytocenotic confinement of the species have been established. Biomorphological and biometric indicators, absolute age of individuals of various age states and their quantitative ratio were determined. Revealed the coincidence of the age groups of the population in terms of age structure and age spectrum, with a characteristic right-sided trend. The population is assessed as young, fullbodied, with a high level of renewability.
\end{abstract}

\section{Introduction}

In the arid conditions of Dagestan, juniper woodlands are one of the main types of communities that are transitional between the shiblyak vegetation of the Foothill and Inner Mountain Dagestan and the pine and deciduous forests of High Mountain Dagestan. Juniper woodlands in Dagestan are represented by three main cenosis-forming species (Juniperus oblonga M. Bieb, Juniperus polycarpos C. Koch, J. sabina L.), where the J.polycarpos is the most important for the conservation of biological diversity - a species listed in the Red Book of RD [1].

Studying the Red Data Book species, determining the reasons for the rarity of the species, the issues of developmental biology become of primary importance. At the same time, the study of these issues is inextricably linked with the issues of the composition and structure of populations, identifying limiting factors and determining ways of selfmaintenance of populations.

Studies of the species J. polycarpos in the world literature are more limited to the study of the taxonomic status and ecology of the species [2, 3, 4], some works provide information on the phytocenotic confinement, seed productivity and the composition of communities with the participation of the species $[5,6]$. At the same time, population

*Corresponding author: sadykova_gula@mail.ru 
issues, as fundamental in the formation of the scientific foundations of the sustainable existence of the species and the development of phytosozological principles and technologies for the conservation of rare species ex situ and in situ, are not widely covered [7] and in the conditions of Dagestan will be considered for the first time in this work.

\section{Methods}

The study of the structure of populations of juniper multifarious was carried out in the Dubkinsko-Miatlinsky area of Foothill Dagestan, located on the western slope of the Nadyrbeg ridge, adjacent to the Sulak River along the Miatlinsky reservoir. The site is located between the Chirkeysky and Miatlinsky reservoirs, near the villages of Dubki and Miatli. Juniper woodlands are found at altitudes from $150 \mathrm{~m}$ (near the Miatlinsky reservoir) to $600 \mathrm{~m}$ (near the Chirkeysky reservoir).

In the flora of juniper woodlands of Foothill Dagestan (in the Dubkinsko-Miatlinsky area), 156 species from 131 genus and 58 families were identified. The dominant communities are the hornbeams (Carpinus orientalis Mill.), Juniper forests (J. polycarpos, single J. oblonga Bieb.), and shiblyaks (with the dominant species Paliurus spina-cristii Mill., Spiraea hypericifolia L.).

Juniper woodlands cover an area of 10 hectares and are confined to the slopes of the northern and northeastern exposures with a steepness of $30-35^{\circ}$.

In the tree layer juniper woodlands dominates J. excelsa subsp. polycarpos, singly occur Quercus petraea subsp. petraea, Fraxinus excelsior, Acer hyrcanum, Carpinus betulus L., Celtis glabrata Stev ex Pianch. Developed polydominant xerophilic undergrowth is formed by shrubs, grass layer is abundant by steppe xerophytes.

The total closeness of the tree and shrub layers is $0.08-0.67$, the projective cover of the herbaceous layer is $30-70 \%$.

Communities juniper woodlands in Dubkinsko-Miatlinsky area of Foothill Dagestan were assigned to 1 association Juniperetum polycarpi xerofruticulosum, 2 subassociation (Spiraeosum hypericifoliae, Jasminosum fruticans) and 7 variants (caricosum humilis, festucosum valesiacae, stiposo-festucosum valesiacae, dictamnosum caucasicae, psathyrostachyosum rupestris, xerofruticosum).

For studying the structure of coenopopulations of the Juniperus polycarpos in the Dubkinsko-Miatlinsky area, were laid 14 test plots of $400 \mathrm{~m} 2$, where all individuals of the J. polycarpos with a height of more than $0.1 \mathrm{~m}$ were counted. For each individual were determined next morphometric characteristics: tree height, tree diameter, diameter of the base of the axial shoot, trunk diameter at a height of $1.3 \mathrm{~m}$, as well as the category of vital state, sex, infestation, fruiting, stage of ontogenesis.

For studying the ontogeny of the J. polycarpos in general, was made a description of 302 individuals of different ontogenetic states: 135 individuals of the pregenerative period, 149 individuals of the generative period and 18 individuals of the postgenerative period.

The calendar age of the trees of the J. polycarpos was determined by cores, which were taken with a Pressler drill at a height of $0.3 \mathrm{~m}$. The counting of tree rings and the derivation of the index (the ratio of the number of rings to the length of the core) was carried out along a larger radius of the trunk to exclude the analysis of the parameters of the heeling wood index characteristic of conifers [8].

The average value of the trunk age index for individuals of this population was $\mathrm{I}=12.5$, with an experimental accuracy of $6,7 \%$.

The grouping of individuals by calendar age was carried out by calculating the class interval using the formula: 


$$
\mathrm{R}=\left(\mathrm{X}_{\max }-\mathrm{X}_{\min }\right) / \mathrm{K}
$$

Which was 50 years, where $\mathrm{K}=5 \mathrm{lgN}$. This interval has a physiological meaning associated with the entry trees J. polycarpos into fruiting at 40-50 years [9].

The category of the vital state of individuals was established on the basis of a complex of crown parameters: the proportion of dry branches, the degree of damage by parasites, the presence and degree of severity of chlorosis in needles. There are 5 categories of the state of individuals: I - withered trees, II - drying trees with severe damage, III - weakened trees, with drying out of individual branches and light chlorosis, IV - individuals in good condition, $\mathrm{V}$ - not depressed (healthy) individuals.

As a basis for determining the stages of ontogenesis of the J. polycarpos was taken the classification of T.A. Rabotnov [10] with additions and clarifications by A.A. Uranov.

Statistical processing of the obtained data was made by using the Statistica 10 software.

\section{Results}

According to the conventional classification of the life cycle of many years of plant seed is divided into four periods: latent, Prega e proliferative, generative and senile.

The latent period lasts from the moment the seeds ripen to the beginning of their germination. Mature seeds of J. polycarpos are brown (from light to dark brown), matte, ovate-oval, ribbed, one-sided concave. The average values of the parameters of seeds at different altitudes and in different cenopopulations are: $4.0-5.5 \mathrm{~mm}(\mathrm{CV}=18.6 \%)$ in length and 2.1-2.6 $\mathrm{mm}$ in width $(\mathrm{CV}=25.3 \%)$, seed weight $4,0-5.5 \mathrm{mg}(\mathrm{CV}=45 \%)$ [11]. According to the results of laboratory studies, using the example of 1 cenopopulation, it was found that the number of normally developed seeds is $36 \%$ [12].

For the pregenerative period (the stage of the plant life cycle from the seedling stage to the beginning of the formation of generative organs), J. polycarpos stage of the seedling and the juvenile individual were omitted.

The stage of the seedling was not evaluated by us due to the fact that with a large number of unfavorable factors their death is possible before the transition to the next stage, as well as with the general short duration of stage by itself.

The transition from the seedling stage to the juvenile stage can also be missed due to the fact that lateral buds form and develop in the axils of the seedling needles, starting from the second and third whorls. That is, the accelerated passage of the juvenile age state and the rapid transition of the seedling to the immature state when assessing and visualizing the ontogenetic spectrum can have a methodological basis and fall out of the spectrum of age states.

Thus, due analyzing the structure of populations individuals J. polycarpos of the pregenerative period, we identified only immature and virginal individuals; seedlings and juvenile plants were not found.

In allocation ontogenetic states of non-generative individuals, the size of the crown and the diameter of the trunk are not of fundamental importance. Biometric indicators of trees of the same genetic state can vary greatly depending on the ecological characteristics of the place of growth: under the rocky ledges, the trees are taller, the trunk diameter is thinner, on the ledges, on the contrary, trees are small in size, while the trunk diameter is much larger. Here, the identifying indicator is the biomorphological structure of the crown, its index and the qualitative characteristics of the shoots and leaves themselves (acicularity, color, openwork or thinness of the crown).

A certain confusion is caused by the affected individuals of Arceuthobium oxycedri (DC.) M. Bieb. They do not form generative organs, while in the initial phases of damage, 
with weakening of seed production, the growth of shoots continues, and the crown index of these individuals can reach 1.3. In case of severe damage, the growth of shoots stops, the shoot dries up as a result of the wedge-shaped penetration of the A. oxycedri haustorium into the bark. In this regard, the affected vegetative individuals without generative organs were assigned by us to the pregenerative group, at later stages of the lesion - to the group of subsenile individuals.

In general, it should be noted that the identification of the ontogenetic state in males also causes certain difficulties, due to the short maturation period of microsporangia and dusting. Therefore, it would be methodologically correct to conduct field studies for isolate the ontogenetic spectrum of coenopopulations of J. polycarpos in the period from March to June - from the moment the microstrobil begins to ripen until the remains of spikelets are preserved.

As a result, young specimens with elongated needle-like needles, which are in the stage of active growth, are classified as immature specimens.

The immature state is characterized by the onset of branching and active growth.

The duration of an individual's stay in a such ontogenetic state depends on both the functional characteristics of the organism and the coenotic growing conditions. In this connection, the height of immature individuals can reach $1 \mathrm{~m}$, the diameter $-1.5 \mathrm{~m}$. Individuals have an elongated needle-like needles. The crown of these individuals differs in varying degrees of branching, the number of lateral shoots greatly varies.

In the virginal state, individuals acquire the habitus of an adult plant, but have not yet entered the seed-bearing phase. Their height and diameter can reach $4.0 \mathrm{~m}$, and the trunk diameters are 2,0-20,0 cm.

It should be noted that a significant spread in the values of the parameters of trees is associated with the microconditions of the environment. Thus, in the mountains, under shading conditions (under rocks), tree trunks are strongly elongated, but there are no signs of entering the generative phase.

Under normal conditions, the crown is of the correct conical shape, the needles are mainly or completely scaly.

Young generative individuals, while maintaining growth activity, enter the seed production phase. The crown is peaked cone-shaped. The total height of the trees is $2.7 \mathrm{~m}$, the diameter is $2.4 \mathrm{~m}$, the diameter of the base of the trunk is $16.8 \mathrm{~cm}$. The needles are scaly, thin, dove-colored, with an abundance of glands at the point of attachment of scales.

In individuals of a mature generative state, maximum seed production is noted. The crown acquires a blunt-topped wide-conical shape due to a decrease in the growth activity of the apical shoots.

The height of trees in this age state is maximum and reaches $5 \mathrm{~m}$. In the crown of mature generative individuals, individual small branches begin to die off. The needles lose their bluish bloom and acquire a dark or light green color.

In individuals of a late generative state, signs of aging processes begin to appear: the activity of seed production decreases, the growth of lateral branches decreases, individual shoots die off in the upper and middle parts of the crown, and the number of dead lower skeletal branches increases.

The crown acquires a sprawling dome-shaped and hemispherical shape, in damaged specimens the crown becomes sparse, unformed.

The average height and crown diameter are 3.8 and $4.3 \mathrm{~m}$, respectively.

The senile individuals of the postgenerative period include individuals without generative organs, both due to physiological old age and as a result of the defeat of Arceuthobium oxycedri.

The height of trees because of various factors entering the post-generative period varies within 1.0-4.8 m, crown diameter 1.2-4.5 m, trunk diameter reaches $37 \mathrm{~cm}$. 
In the lower part of the crown, the proportion of dying branches reaches $30 \%$. The trunk is often twisted. The crown acquires an irregular, hemispherical, less often umbellate shape, with a looser structure, which is formed due to an increase in the proportion of bare branches in the inner part of the crown.

Table 1. Parameters of Juniperus polycarpos specimens of different ontogenetic stages in the dubkinsko-miatlinsky area.

\begin{tabular}{|c|c|c|c|c|c|c|c|}
\hline \multirow{2}{*}{$\begin{array}{c}\text { Parame } \\
\text { ters }\end{array}$} & \multicolumn{7}{|c|}{ Ontogenetic states } \\
\hline & im & $\mathbf{v}$ & g1 & g2 & g3 & SS & $\mathbf{s}$ \\
\hline $\begin{array}{c}\text { Tree } \\
\text { height, } \mathrm{m}\end{array}$ & $\begin{array}{c}0,5 \pm 0,0 \\
4 \\
0.11- \\
1.0 \\
\end{array}$ & $\begin{array}{c}1.8 \pm 0.0 \\
6 \\
0.7-4.0\end{array}$ & $\begin{array}{l}2.7 \pm 0.1 \\
1.0-5.5\end{array}$ & $\begin{array}{c}3,2 \pm 0 \\
19 \\
1,7- \\
5,0\end{array}$ & $\begin{array}{c}3,8 \pm 0,2 \\
5 \\
3,5-4\end{array}$ & $\begin{array}{c}3,1 \pm 0,25 \\
1,0-4,8\end{array}$ & $\begin{array}{c}1,8 \pm 0 \\
1,8\end{array}$ \\
\hline $\begin{array}{c}\text { Crown } \\
\text { diameter, } \\
\mathrm{m}\end{array}$ & $\begin{array}{c}0.39 \pm 0 . \\
04 \\
0.03- \\
1.5 \\
\end{array}$ & $\begin{array}{c}1.5 \pm 0.0 \\
6 \\
0.5-4.0\end{array}$ & $\begin{array}{c}2.4 \pm 0.0 \\
7 \\
0.6-4.5\end{array}$ & $\begin{array}{c}3,6 \pm 0 \\
22 \\
2,0- \\
6,0 \\
\end{array}$ & $\begin{array}{c}4,3 \pm 0,2 \\
5 \\
4,0-4,5\end{array}$ & $\begin{array}{c}3,1 \pm 0,25 \\
1,2-4,5\end{array}$ & - \\
\hline $\begin{array}{c}\text { Trunk } \\
\text { base } \\
\text { diameter, } \\
\text { sm }\end{array}$ & $\begin{array}{c}2.32 \pm 0 . \\
26 \\
0.3-8.0\end{array}$ & $\begin{array}{c}9.0 \pm 0.4 \\
9 \\
2.0-20.0\end{array}$ & $\begin{array}{c}16.8 \pm 0 . \\
69 \\
3.0-35.0\end{array}$ & $\begin{array}{c}24,2 \pm \\
1,4 \\
10,0- \\
40,0 \\
\end{array}$ & $\begin{array}{c}28,5 \pm 1, \\
5 \\
27,0- \\
30,0 \\
\end{array}$ & $\begin{array}{l}21,6 \pm 2,0 \\
5,0-37,0\end{array}$ & $18,0 \pm 0$ \\
\hline $\begin{array}{c}\text { Trunk } \\
\text { diameter } \\
\text { at a } \\
\text { height of } \\
0.3 \mathrm{~m} \\
\end{array}$ & $\begin{array}{c}1.5 \pm 0 \\
1.5\end{array}$ & $\begin{array}{c}6.6 \pm 0.5 \\
2 \\
2.0-15.0\end{array}$ & $\begin{array}{c}14.4 \pm 0 . \\
7 \\
2.0-30.0\end{array}$ & $\begin{array}{c}20,6 \pm \\
2,0 \\
10,0- \\
35,0\end{array}$ & $\begin{array}{c}26,0 \pm 1 \\
0 \\
25,0- \\
27,0\end{array}$ & $\begin{array}{l}18,8 \pm 1,8 \\
3,5-34,0\end{array}$ & $15,0 \pm 0$ \\
\hline $\begin{array}{c}\text { trunk } \\
\text { diameter } \\
\text { at a } \\
\text { height of } \\
1,3 \mathrm{~m}\end{array}$ & - & $\begin{array}{c}3.1 \pm 0.3 \\
8 \\
0.5-10.0\end{array}$ & $\begin{array}{c}10,3 \pm 0 \\
74 \\
3,0-25,0\end{array}$ & $\begin{array}{c}13,9 \pm \\
2,2 \\
7,0- \\
25,0\end{array}$ & $\begin{array}{c}12,0 \pm 0 \\
12\end{array}$ & $\begin{array}{c}10,4 \pm 1,3 \\
2,5 \pm 22\end{array}$ & - \\
\hline
\end{tabular}

Note: above the line - the average value and the error of the average, below the line - the range of values.

\section{Discussion}

To assess the reliability of the identification of groups, cluster analysis was carried out for the main quantitative characteristics of trees (crown height and diameter, trunk diameter at the base, crown index). According to the traits taken into account, the individuals were grouped into 6 main clusters, corresponding to the number of identified ontogenetic states (the analysis did not include withered - senile individuals).

According to the results of cluster analysis, the trees were divided according to biometric indicators into 2 large groups (fig.1). The first group (1) included smaller individuals, the second - larger ones. The first group included immature, virginal and young generative individuals, up to $2.7 \mathrm{~m}$ in height and up to 12 years of base diameter. The second group included $73 \%$ of generative individuals and the largest of the virginal and subsenile individuals. The age of individuals in the first cluster varies from 187 to 500 years, in the second from 10 to 162 years.

At the second level, the gradation took place according to more similar biometric groups.

Cluster 1.1 included all immature individuals and 2 samples of the generative and postgenerative state with low values of the tree diameter, that is, the 1.1 cluster was distinguished by the tree diameter. 
In cluster 1.2 , mainly virginal individuals $(68.6 \%)$ and young generative individuals $(26.8 \%)$ with average values of the height $(1.7 \mathrm{~m})$ and diameter $(1.3 \mathrm{~m})$ of the tree were isolated.

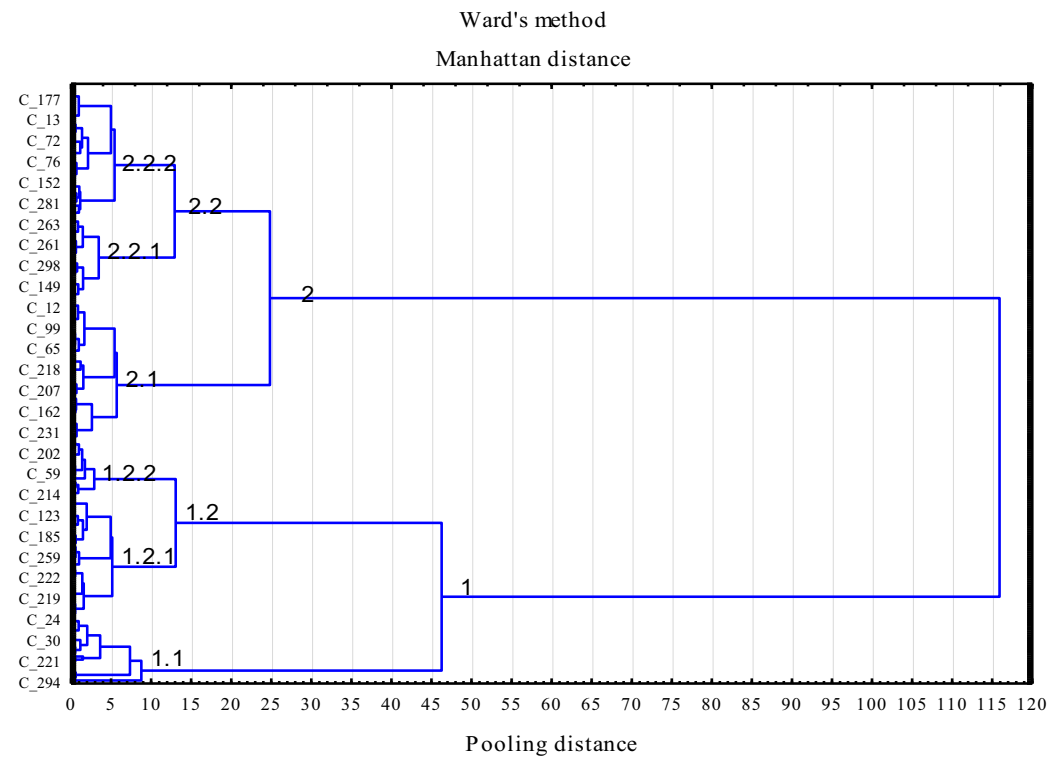

Fig. 1. Diagram of cluster analysis on biometric parameters of individuals J. polycarpos.

Cluster 2.1 included old-age individuals with the largest biometric parameters, in 2.2 individuals up to 275 years old with slightly lower values of the height and diameter of the bush.

Further differentiation is based on the diameter of the tree base (age). 1.2.1 cluster consists of middle-aged individuals - from 50 to 150 years old, 1.2.2 - younger individuals (from 25 to 88 years old), etc. Index indicators of individuals turned out to be of little informative.

Thus, when allocating clusters despite high interdependence biometric data of individuals, the main feature served as the barrel diameter at the base, which is confirmed by analysis of variance logarithmic values recorded characteristics where the greatest value of F - criterion is observed on the basis of "base diameter" (Table. 2, Fig. 2).

Table 2. Analysis of variance logarithmic characteristic values trees $\mathrm{J}$. polycarpos.

\begin{tabular}{|l|c|c|c|c|c|c|}
\hline & $\begin{array}{c}\text { Between } \\
\text { SS }\end{array}$ & df & Inside SS & df error & F & p \\
\hline Bush height $\mathrm{m}$ & 18.79572 & 5 & 3.036901 & 281 & 347.8281 & 0.000000 \\
\hline Crown diameter, $\mathrm{m}$ & 26.81311 & 5 & 4.626929 & 281 & 325.6797 & 0.000000 \\
\hline Base diameter, sm & 36.78245 & 5 & 4.837759 & 281 & 427.2998 & 0.000000 \\
\hline Crown index & 3.13625 & 5 & 3,788304 & 281 & 46.5267 & 0.000000 \\
\hline
\end{tabular}




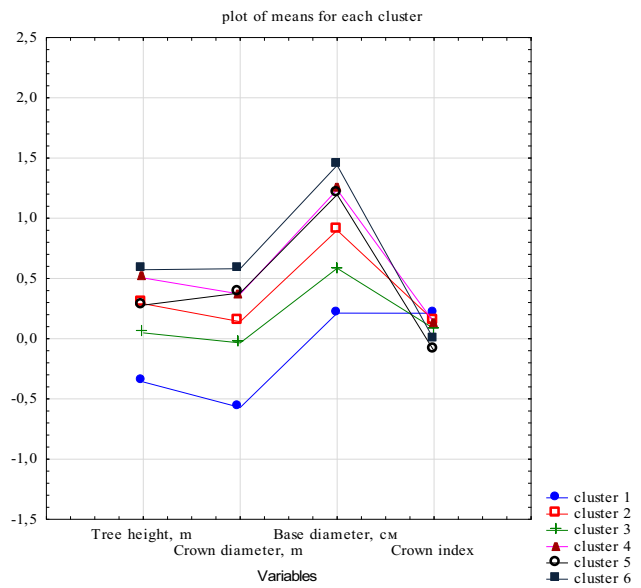

Fig. 2. Graph of means for each cluster using the K-means method.

Considering this fact, as well that the assessment of the calendar age is carried out by recalculating the trunk index by its diameter, we can say that the allocation of clusters is more related to the calendar age of individuals.

The distribution of individuals of different age states in the classes of absolute ages (Fig. 3, Table 3) has a classical scheme of the distribution of ontogenetic states by calendar ages.

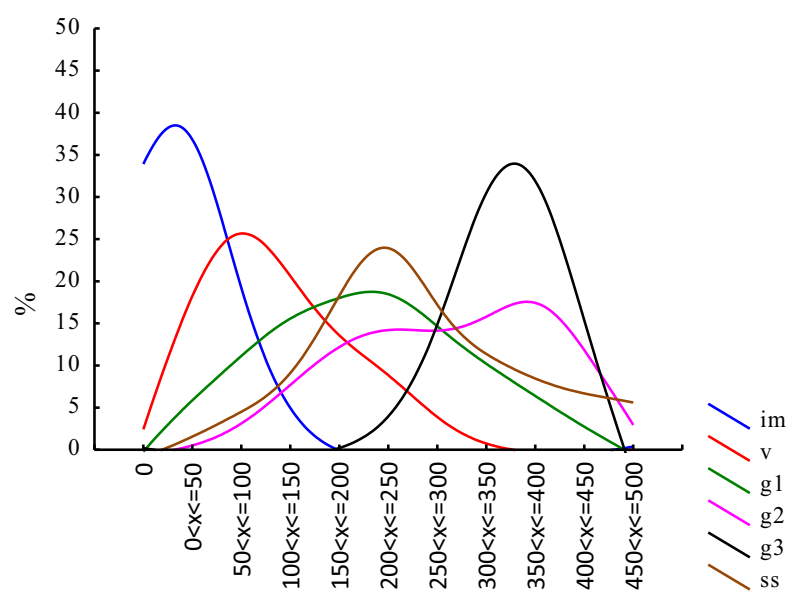

Fig. 3. Approximated least squares graph, \%.

In immature individuals, the average age is 23 years, for virginal individuals it is 111 years old and can reach 250 years. The age of individuals of the young generative state ( $\mathrm{g}$ 1 ) is in the range of 38-438 years. The bulk of old-age individuals are in late generative, slightly less in mature generative states. The average age of individuals is $\mathrm{g} 2$ - 303 years, $\mathrm{g}$ 3 - 356 years.

A deviating from the normal distribution with a left-sided trend is the distribution of individuals of the subsenile age state, the largest number of which falls within the range from 150 to 350 years. We associate this distribution with the infection of individuals. 
Table 3. Distribution of individuals of different ontogenetic groups by calendar ages.

\begin{tabular}{|c|c|c|c|c|c|c|c|c|c|c|c|c|}
\hline Age & im & & $\mathbf{v}$ & & g1 & & g2 & & g3 & & ss & \\
\hline & $\mathrm{n}$ & $\%$ & $\mathrm{n}$ & $\%$ & $\mathrm{n}$ & $\%$ & $\mathrm{n}$ & $\%$ & $\mathrm{n}$ & $\%$ & $\mathrm{n}$ & $\%$ \\
\hline 0 & 8 & 20 & 1 & 1,05 & 0 & 0 & 0 & 0 & 0 & 0 & 0 & 0 \\
\hline $0<\mathrm{x}<=50$ & 30 & 75 & 15 & 15,79 & 7 & 5,93 & 0 & 0 & 0 & 0 & 0 & 0 \\
\hline $50<\mathrm{x}<=100$ & 2 & 5 & 42 & 44,21 & 10 & 8,47 & 0 & 0,0 & 0 & 0 & 1 & 6,25 \\
\hline $100<\mathrm{x}<=150$ & 0 & 0 & 16 & 16,84 & 22 & 18,64 & 2 & 6,90 & 0 & 0 & 0 & 0 \\
\hline $150<\mathrm{x}<=200$ & 0 & 0 & 8 & 8,42 & 16 & 13,56 & 4 & 13,79 & 0 & 0 & 2 & 12,5 \\
\hline $200<\mathrm{x}<=250$ & 0 & 0 & 13 & 13,68 & 31 & 26,27 & 5 & 17,24 & 0 & 0 & 8 & 50 \\
\hline $250<\mathrm{X}<=300$ & 0 & 0 & 0 & 0 & 12 & 10,17 & 3 & 10,34 & 0 & 0 & 0 & 0 \\
\hline $300<\mathrm{X}<=350$ & 0 & 0 & 0 & 0 & 11 & 9,32 & 3 & 10,34 & 1 & 50 & 2 & 12,5 \\
\hline $350<\mathrm{x}<=400$ & 0 & 0 & 0 & 0 & 7 & 5,93 & 9 & 31,03 & 1 & 50 & 1 & 6,25 \\
\hline $400<\mathrm{x}<=450$ & 0 & 0 & 0 & 0 & 2 & 1,69 & 2 & 6,90 & 0 & 0 & 1 & 6,25 \\
\hline $450<\mathrm{x}<=500$ & 0 & 0 & 0 & 0 & 0 & 0 & 1 & 3,45 & 0 & 0 & 1 & 6,25 \\
\hline
\end{tabular}

In general, the distribution of individuals by ontogenetic state has a right-sided asymmetry, with a predominance of individuals of the pre-generative period and the young generative state (Fig. 4).

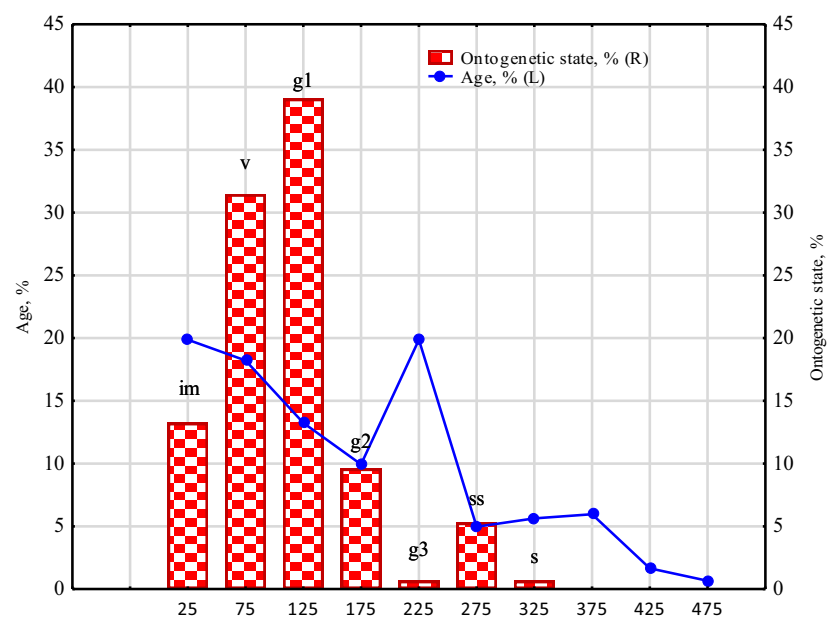

Fig. 4. Distribution of J. polycarpos individual's calendar age and age state in the Dubkinsko-Miatlinsky population.

Note: The distribution of species on the developmental states in the graph does not match the class of absolutely ages and should be considered independently.

The distribution of individuals by calendar ages has a two-peak curve with a maximum in the group of young individuals under 25 and 225 years old.

Maximum calendar age individuals $\mathrm{J}$. polycarpos in the cenopopulation reaches 500 years, the average age is 168 years. The approximation line has a right-hand trend.

The following distribution of individuals by age groups is observed: $19.9 \%$ up to 50 years old, $18.2 \%$ up to 100 years old, $13.2 \%$ up to 150 years old, $9.9 \%$ up to 200 years old, $19.9 \%$ up to 250 years old, $18.9 \%$ of individuals are over 250 years old (Table 3 ) .

The general age trend also has a right-sided asymmetry, with the maximum age range characteristic for the species, which characterizes the cenopopulation as absolutely different in age, stable, capable of long-term self-maintenance.

Such a ratio of the calendar age of individuals in the cenopopulation and their ontogenetic state indicates the stability and high renewability of the population. 


\section{Conclusions}

The ontogenetic spectrum of the coenopopulation J. polycarpos in the foothill Dagestan in the Dubkinsko-Miatlinsky area is full-term spectrum, with a predominance of pregenerative (virginal - 33\%) and young generative individuals (36\%). Individuals of late generative, subsenile, and senile states take the least part in the community. The presence of individuals of subsenile and senile states in the coenopopulation is the result of the action of parasites (Arceuthobium oxycedri (DC.) M. Bieb.), as well as abiotic (mechanical, physical) environmental factors.

The maximum calendar age individuals J. polycarpos in the cenopopulation is 500 years old, the average age is 168 years.

In general, there is a coincidence of the spectra, with a characteristic right-sided trend. The population is assessed as a young full-term, with a predominance of pregenerative and young generative individuals.

\section{References}

1. Red Book of the Republic of Dagestan (Makhachkala, 2020)

2. F. Martin, A. S. Gardner, Vegetatio, 119 (1995)

3. R.P. Adams, M. Armagan, B. Douaihy et al., Phytologia, 98, 2 (2016)

4. F. Hojjati, SH. Kazempour-Osaloo, R. P. Adams, M. Assadi, Phytotaxa, 375, 2 (2018)

5. D. Kartoolinejad, A. Moshki, Austrian J. forest science, 4 (2014)

6. M. Mohammadi Zade, H. Kiadaliri, V. Etemad, I. Mehregan, Egyptian J. Botany, 58, 3 (2018)

7. A. Singh, S.S. Samant, Arid ecosystems, 26, 1 (2020)

8. V.F. Razdorsky, Plant Architectonics (Soviet Science, Moscow, 1955)

9. A.A. Grigoryan, Materials of the first all-Union meeting on the "Juniper problem" (Publishing House of the Academy of Sciences of the Armenian SSR, Yerevan, 1976)

10. T.A. Rabotnov, Problems of botany, 1 (1950)

11. G.A. Sadykova, Z.M. Asadulaev, Povolzhskiy Ecol. J., 2 (2016)

12. G.A Sadykova, Bot. Bull. of the North Caucasus, 1 (2019) 